
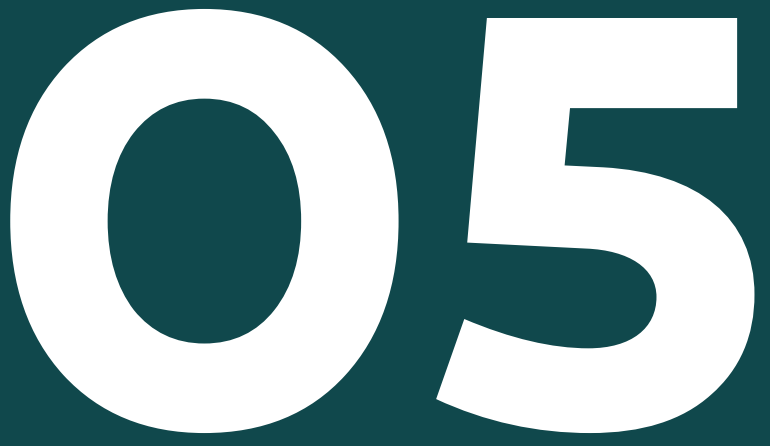

\title{
Redes sociales: una herramienta de distribución promocional del marketing turístico
}

Social networks: a promotional distribution tool for tourism marketing

FECHA DE RECEPCIÓN: 24/03/2021

FECHA DE APROBACIÓN: 15/05/2021

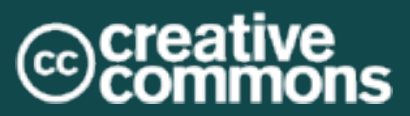




\section{Resumen}

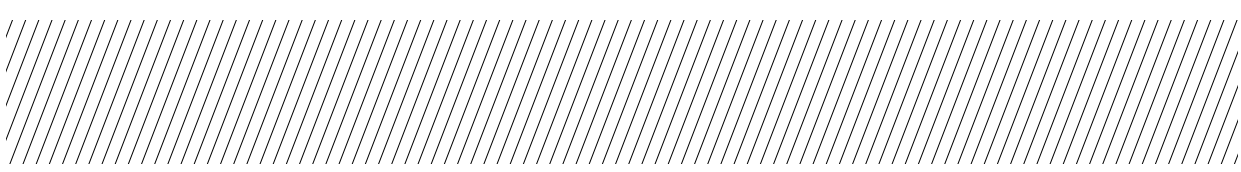

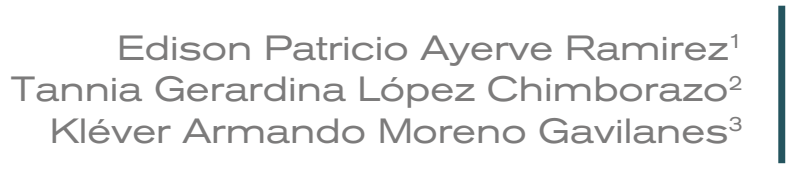

El proceso de comunicación en el sector turístico se ve influenciado por reseñas, comentarios u opiniones generados en las plataformas digitales. Este factor puede influenciar a los compradores y ser percibida de manera positiva o negativa. El objetivo de la investigación fue evaluar los efectos de las redes sociales en la industria turística, mediante el modelo de aceptación y tecnología (TAM). La metodología utilizada fue cuantitativa, porque permitió la recopilación de información con el fin de describir el problema y señalar las correlaciones causales del inadecuado uso de redes sociales en el sector turístico. La población de estudio pertenece a la provincia de Tungurahua. De allí, se utilizó un muestreo aleatorio-simple de 384 personas bajo el criterio de selección de economía activa (PEA). El resultado demostró que las redes sociales como Facebook, Instagram y WhatsApp son idóneas para realizar promoción turística. Se concluye, que la promoción del sector turístico tiene mayor influencia en la plataforma de Instagram, puesto que, muestra mayores beneficios y desventajas alarmantes al socializar contenido frente a otro medio social.

Palabras clave: distribución promocional, marketing turístico, redes sociales.

1 Universidad Técnica de Ambato · patricioramirez634@gmail.com • https://orcid.org/0000-00031524-5644 - Ambato, Ecuador

2 Universidad Técnica de Ambato · tania_geraldina@hotmail.com • https://orcid.org/0000-00030931-9774 - Ambato, Ecuador

3 Universidad Técnica de Ambato · kleveramoreno@uta.edu.ec · https://orcid.org/0000-0001-98708821 - Ambato, Ecuador 


\section{Abstract}

T

he communication process in the tourism sector is influenced by reviews, comments or opinions generated on digital platforms. This factor can influence buyers and be perceived positively or negatively. The objective of the research was to evaluate the effects of social networks in the tourism industry through the acceptance and technology model (TAM). The methodology used was quantitative, because the collection of information in order to describe the problem and point out the causal correlations of the inappropriate use of social networks in the tourism sector. The study population belongs to the province of Tungurahua. From there, a simple-random sampling of 384 people was used under the active economy selection criterion (PEA). The result showed that social networks such as Facebook, Instagram and WhatsApp are ideal for promoting tourism. It is concluded that the promotion of the tourism sector has a greater influence on the Instagram platform, since it shows greater benefits and alarming disadvantages when socializing content compared to another social medium.

Keywords: promotional distribution, tourism marketing, social networks.

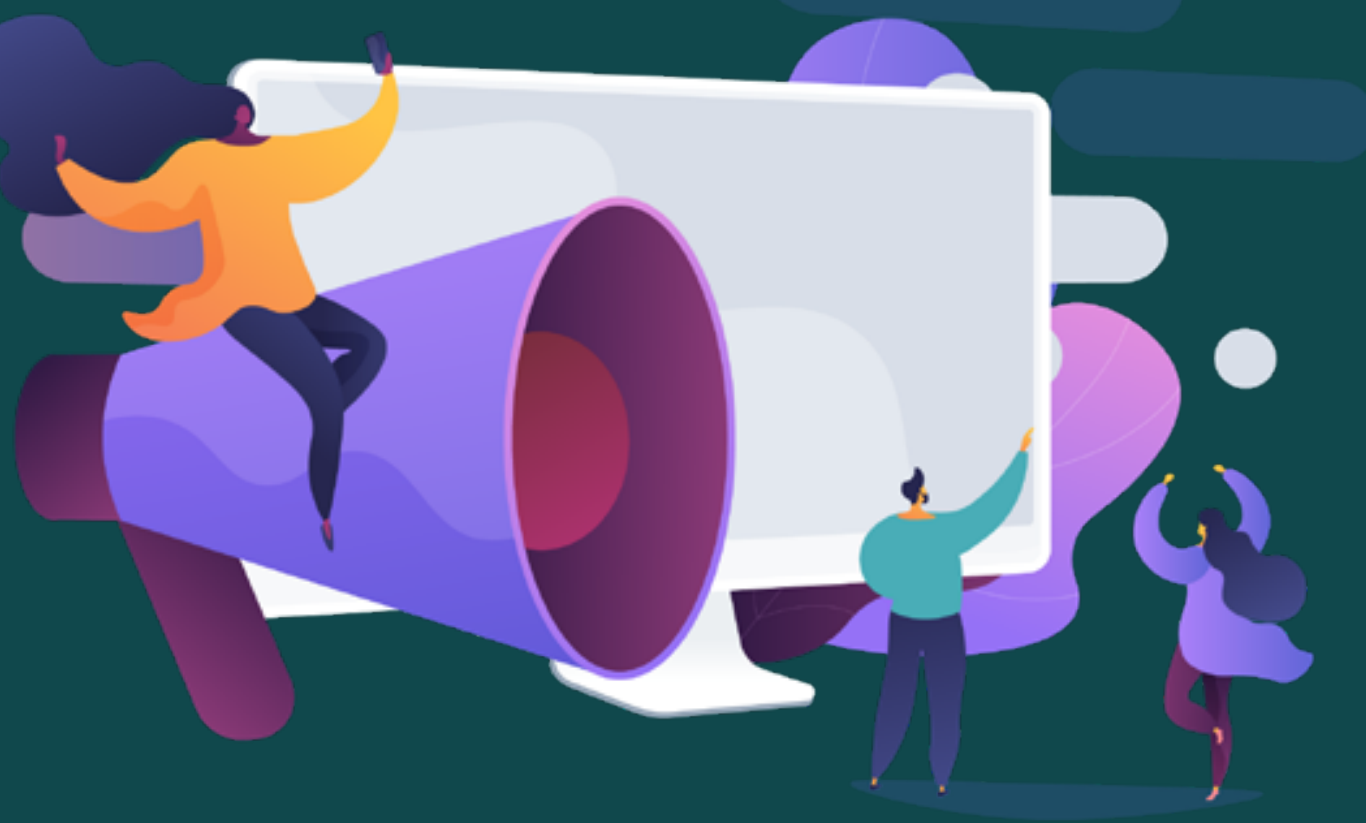




\section{Introducción}

- I inicio de las redes sociales como herramienta en el sector del turismo es incierta, sin embargo, los principales medios de promo-

ción se iniciaron con folletos, artículos y publicaciones en medios tradicionales (Nazimsha \& Rajeswari, 2018); por lo tanto, la comunicación de masas solo estaba dispuesta en canales definidos y limitados. Con la llegada de la comunidad virtual en el año 2004, a través de la web 2.0 fue transformada la información y difusión, dando dio inicio a páginas web de empresas turísticas, folletos y revistas online entregadas por email y sugerencias (Khan, Abduljabbar, \& Alsamarai, 2019).

La información que era entregada al consumidor sobre ofertas turísticas, mantenía la interactividad con otros usuarios acerca de experiencias adquiridas (Sharma \& Bhatnagar, 2016); pues, una comunidad en línea exitosa, ayudó a fortalecer la lealtad de marca de los consumidores y sirvió como canal para la comunicación y el intercambio del conocimiento (Gulati, 2021)very few studies have explored the impact of social media on sustainable tourism, and thus, it can be said to be in its \»infancy\» (Han et al., 2017. Dichas agrupaciones no solo funcionaban como un medio entre clientes, sino también, como una herramienta importante para construir relaciones con ellos.

En la actualidad, un gran número de personas prefieren viajar a un destino turístico con alternativas de comunicación y planificación en línea. Esto se debe a la comodidad que representa la comparación de precios, reseñas u opiniones, calificación del sitio, seguridad, complejidad de llegada, entre otros. De hecho, el estudio denominado, las redes sociales y el turismo: importancia de las redes sociales sobre la estrategia empresarial del sector turístico demostró que, el 52\% de turistas, han sido influenciados por fotografías subidas en la comunidad virtual; por lo tanto, la oferta turística optó por adaptarse a la nueva tendencia de comportamiento, volviéndose cada vez más activa en redes sociales. Las ofertas turísticas han revolucionado sus interacciones comunicativas y de comercialización, dando paso a estrategias empresariales basadas en el área virtual (Mestanza, 2015). 
La medición del valor de un negocio desde las tecnologías de la información y la comunicación, han sido tradicionalmente problemáticas, pues, los medios sociales son diferentes a los medios tradicionales, ya que, requieren un enfoque diferente para su evaluación (Joel \& Armas, 2021). Si bien es cierto, el impacto de la actividad online se puede medir utilizando métricas cuantitativas definidas, pues, las redes sociales generan una cantidad considerable de datos cualitativos que las métricas tradicionales, por sí solas, no logran abordar o cuantificar en términos monetarios.

En diciembre del año 2019, al registrase la pandemia mundial por COVID-19, la Organización Mundial del Turismo (2020) logró prever la reducción del $50 \%$ y $78 \%$ del sector turístico; es decir, alrededor de 120 millones de puestos de trabajo podrían estar en peligro, así como, una pérdida inminente de 1,200 billones de dólares en exportaciones. Por otro lado, se pronosticó que la recuperación de afluencia turística en América Latina y El Caribe sería a partir de octubre del 2020 (Organización Mundial del Turismo, 2020).

En el contexto de Ecuador, el Producto Interno Bruto (PIB) entre el primer trimestre del año 2015 al cuarto trimestre del año 2019, el turismo receptó un promedio de 1,9\% del PIB, lo que equivaldría a 490 millones de dólares; mientras que, la salida de divisas por turistas ecuatorianos 0 turismo emisor es de 345 millones de dólares (Cortés \& Alcantara, 2020). No obstante, el informe de Ecuador Estado Digital 2021 asegura que el $78,7 \%$ de los ciudadanos en el país usa redes sociales; es decir, alrededor de 14 millones de personas mantienen cuentas activas, de ellas, las más populares son Facebook, Instagram, TikTok y Twitter. De hecho, el estudio reveló que una persona pasa 18,50 minutos al día en Facebook y revisa alrededor de 9 páginas alternas, que hacen referencia a la publicidad emitida en esta red social (del Alcázar, 2021).

Este estudio tuvo como objetivo evaluar los efectos de las redes sociales en la industria turística, pues, analiza las evidencias más importantes sobre el Modelo de Aceptación y Tecnología (por sus siglas en inglés, TAM) que estudia las aristas de influencia percibida, facilidad de uso que finaliza en las decisiones turísticas.

El escenario hipotético se planteó mediante un modelo de incidencia teórica del modelo TAM, es decir, que su planteamiento se lo 
llevó a través del análisis de estudios previos para identificar su relación teórica con las variables de estudio. Por lo tanto, la investigación tuvo como fundamento la influencia percibida expresada en interacciones, relacionadas con el disfrute y la comunicación boca a boca (eWOM) en redes sociales.

\section{Promoción Turística}

La promoción es la acción y efecto de impulsar o tomar la iniciativa. Dicho término puede utilizarse para nombrar actividades que buscan incrementar las ventas de un bien o un servicio. Por tal razón, la idea de promoción turística hace referencia a la difusión de un lugar como destino para los turistas. Cabe recalcar que, el turismo es un elemento intangible que genera interés al turista mediante sus locaciones, platos típicos, costumbres, hostería y agencias de viaje que conciben mayores ingresos económicos; allí, la importancia de la promoción turística (Alfonso, García, \& Rodríguez, 2017).

La promoción turística analiza la difusión de un destino turístico; en este sentido, Castillo y Cataño (2015) aseveran que la promoción turística proporciona conocimiento de la infraestructura y los atractivos de un lugar, donde prevalece la confianza, seguridad y diferenciación de la competencia, pues, esto influye en el proceso de compra. Por lo tanto, determinar cierta información para que la recepte de manera sencilla, beneficia a la trasmisión del mensaje, promoviendo de manera eficaz el destino turístico.

La promoción turística abarca ciertos objetivos específicos que son de importancia para su aplicación efectiva: a) Promover el atractivo turístico de un lugar, país o ciudad, b) Dar a conocer ofertas turísticas, c) Desarrollar eventos de cierta relevancia y d) Impulsar la cultura y costumbres del lugar para atraer a mayor número de visitantes (Joel \& Armas, 2021).

La información visual proporciona una experiencia directa, pues, influye en el atractivo turístico a través de una imagen. En otras 
palabras, el destino puede transportar al cliente hacia un lugar que aún no ha sido visitado por medio de señales visuales. En este sentido, el uso de fotografías, imágenes en $360^{\circ}$ y videos multimedia, favorecen a la información promocional e incremento de visitantes para mejorar la imagen positiva del destino. Es por ello, que se consideran nuevas técnicas de promoción turística como: el Cine, catalogada como una experiencia postmoderna que expone atractivos y características particulares, que pueden influir en las preferencias de viaje de un individuo. Advergames móvil, es el uso de juegos interactivos de publicidad que buscan nuevos consumidores del mercado objetivo (Castillo y Cataño, 2015).

Para establecer una promoción turística, se considerar cinco características de comunicación efectiva: a) fuente emisora que determine el destino turístico, b) público meta, c) mensaje a trasmitir, d) medio de difusión; y, e) mecanismos de retroalimentación que establezcan resultados (Joel \& Armas, 2021; Singh, 2019). Sobre lo establecido, se dio paso a las siguientes relaciones hipotéticas:

H1. La utilidad percibida afecta la actitud del turista en el uso de las redes sociales en el proceso de compra.

H2. La facilidad de uso percibido influye, directamente, con la actitud del turista en el uso de las redes sociales en el proceso de compra.

\section{Las redes sociales como promoción turística}

Para iniciar una promoción turística en redes sociales se debe tomar en cuenta la popularidad de cada una de ellas, pues, el número de usuarios en estas plataformas sigue creciendo día a día (Bodle, 2015). La ventaja de las redes sociales es que los usuarios están dispuestos a compartir información sobre sus gustos y disgustos, lo que facilita un mayor control de público objetivo. Por tanto, los beneficios que brinda este medio es presentar contenido comercial determinado, con el fin de atraer a clientes potenciales. La mayoría de las empresas optan por un plan estratégico que contenga el valor de marca, pues, no solo promocionan una locación, ciudad o país sino, también, un concepto (Gutauskas, 2019). 
Muchas de las páginas turísticas promocionadas en redes sociales desarrollan su propia aplicación móvil, pues, los viajeros esperan usarlas para reservar habitaciones, pagar servicios, guías turísticas, planes de actividades, entre otros (García \& Sánchez, 2014). Un elemento clave de las redes sociales como herramienta de marketing es que los propios usuarios crean el contenido subiendo fotos o experiencias del lugar, generando otra forma de publicidad y promoción (Singh, 2019).

La utilidad percibida de las redes sociales, permite que la difusión sea tan rápida que puede hacer o deshacer cualquier agencia, pues, las redes sociales tienen la ventaja de llegar a una audiencia global, incluso, en recónditos a nivel global (Félix \& García, 2020). De este modo, un comentario excelente puede llegar a ser viral, como también puede acontecer con las críticas indebidas o información inexacta. El impacto de las redes sociales ha ganado popularidad a medida que los consumidores recurren a las redes en línea para compartir ideas, sugerencias, fotos y videos, mientras que, desarrollan amistades dentro de una comunidad virtual.

\section{Por tanto, sobre esta base se hipotetizó las siguientes relaciones:}

H3. La actitud del turista en el uso de las redes sociales, influye directamente en la intención de comportamiento al utilizar tecnología para elegir un destino turístico.

H4. El disfrute percibido de las redes sociales, afecta la utilidad percibida en la comunicación.

H5. La facilidad de uso percibida tiene un efecto directo sobre el disfrute percibido.

H6. El disfrute tiene una influencia directa en la actitud hacia las redes sociales. 


\section{Proceso de comunicación de las redes sociales}

Las comunidades virtuales demandan un gran conocimiento de interés, comportamiento, consumo de medios y decisión de compra de los consumidores. Es por ello, que el proceso de comunicación en las redes sociales debe ser comprendido por las principales perspectivas de community manager, responsables de planificar e implementar sistemas y recursos para incrementar la comunicación (Sanchis, 2013).

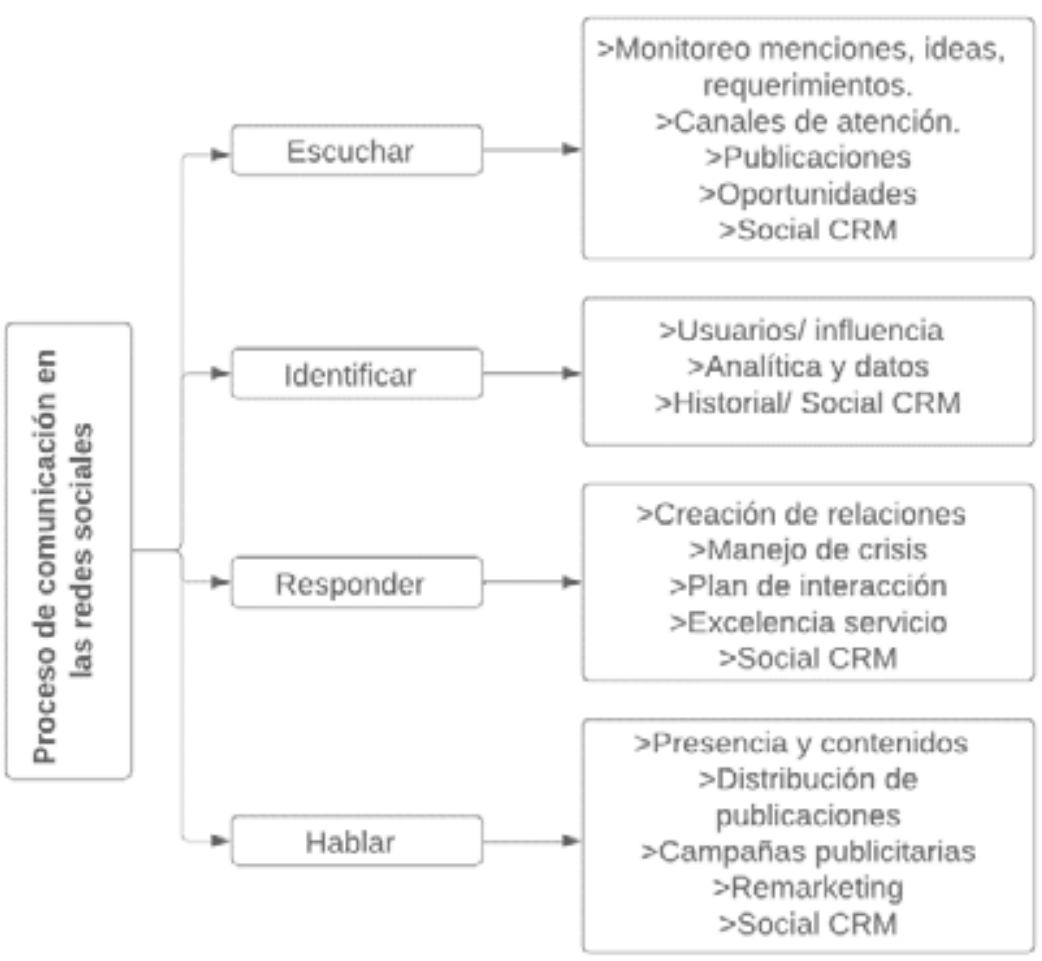

Figura 1. Proceso de comunicación en las redes sociales

Nota. El modelo gráfico fue adaptado de García \& Sánchez (2014); Gutiérrez, Sánchez, \& Galianol (2018). 
El proceso de comunicación en las redes sociales se divide en cuatro fases: Escuchar, hace referencia al monitoreo, menciones y requerimientos que realiza el consumidor a través por medio de los canales de atención que pueden ser telefonía, chats, social media, entre otros (García \& Sánchez, 2014; Gutiérrez, Sánchez, \& Galianol, 2018). Cabe recalcar que, las publicaciones efectuadas dan paso a oportunidades de interacción Customer Relationship Management (Social CRM): Identificar, el nivel de influencia que tienen los usuarios en las redes sociales, mediante estadísticas de rangos sociodemográficos y la interacción que presenta cada una de sus visitas. Responder, la pronta respuesta que genera el emisor. Crear, las relaciones al despejar dudas de los usuarios, del que dependerá el nivel de servicio desde su perspectiva. Hablar, los contenidos, publicaciones, campañas publicitarias y el Remarketing, realizados por el emisor de manera constante, aseguran la relación entre el consumidor y el producto/servicio.

\section{Dado que el proceso de comunicación (eWOM) en las redes sociales abarca diversas fases se hipotetizó lo siguiente:}

H7. El eWOM tiene una influencia directa en la utilidad percibida de las redes sociales.

H8. El eWOM afecta el disfrute percibido.

H9. El eWOM tiene una influencia directa en la actitud del turista al usar las redes sociales; se grafica el proceso del modelo teórico identificado, según el marco de hipótesis señalado: 


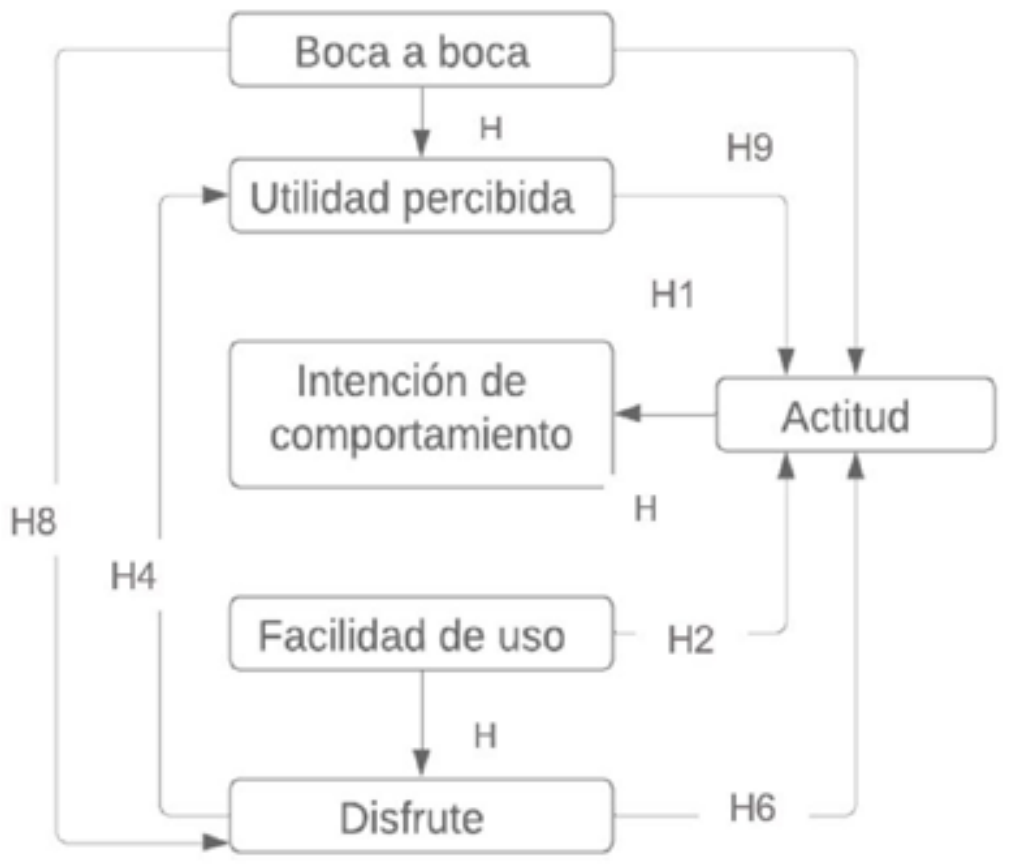

Figura 2. Hipótesis

Fuente. Elaborado por los autores. 


\section{Método}

Para recopilar información sobre la distribución promocional del marketing turístico en las redes sociales de la provincia de Tungurahua, se utilizó el método correlacional de investigación, que permitió la recopilación sobre las condiciones existentes de promoción. Los principales objetivos al emplear este método es describir el problema y señalar las causas del adecuado o inadecuado uso de las redes sociales en el sector turístico.

Se utilizó la modalidad de campo para el levantamiento de datos, que fue obtenida de la aplicación del cuestionario validado por Di Pietro et al. (2012), que está constituido de tres dimensiones. Este constructo se lo denomina modelo de aceptación y tecnología (TAM); su propósito, es explicar de manera simplificada los factores que determinan el uso de las TIC por un gran número de usuarios. En este punto, se detalla: la primera, se encargó de identificar qué elementos de las redes sociales se utilizan; la segunda, evaluó los efectos positivos y negativos de las redes sociales; la tercera, determinó los problemas que se encontraron al usar las redes sociales.

El instrumento constó de 25 elementos diseñados mediante un nivel escalar de Likert de 5 puntos, donde $1=$ Totalmente en desacuerdo; $2=$ En desacuerdo; $3=$ Indiferente; $4=$ De acuerdo; $5=$ Totalmente acuerdo. Como unidad de análisis se tomó a la Población Económicamente Activa (PEA) de la provincia de Tungurahua, donde se obtuvo una muestra probabilística de tipo aleatorio simple de 384 personas. Por razones de protocolo de bioseguridad, la recolección de información se la llevó a cabo a través de Google Drive (encuestas digitales). La muestra del estudio se estableció por medio de un muestreo tipo probabilístico, al tomar la población económicamente activa (PEA) (ver tabla 1). La validación del instrumento mediante el coeficiente de fiabilidad del alfa de Cronbach, determinó mediante la correlación de las varianzas de cada ítem, variables y medidas que, es aceptable dado que su valor $\alpha=, 886$ y se aproxima a 1. 
Tabla 1.Ficha técnica de investigación

\begin{tabular}{ll}
\multicolumn{1}{c}{ Parámetro } & \multicolumn{1}{c}{ Descripción } \\
\hline Muestra de estudio & 384 Personas Económicamente Activas \\
Entorno & Provincia de Tungurahua-Ambato \\
Método de captación & Encuesta \\
Procedimiento & Muestreo de tipo probabilístico \\
Nivel de confianza & $95 \%$ \\
Margen de error & $5 \%$ \\
Cuestionarios validados & 384 \\
\hline
\end{tabular}

Fuente. Elaborado por los autores.

\section{Resultados}

El procesamiento de información obtenida de la encuesta determinó el perfil sociodemográfico. Se identificó que, el $61,2 \%$ de los consumidores son mujeres, poseen una edad entre 25 y 30 años; de este porcentaje, el $43,1 \%$ son empleados públicos con un gasto estimado en los lugares turísticos de 100 y 300 dólares y su preferencia a viajar es con familia (ver tabla 3). Por otro lado, el estudio denominado perfil sociodemográfico del turista, aseveró que la tendencia a visitar lugares turísticos, mantiene un porcentaje mayoritario del $48,8 \%$ entre familiares y amigos, pues, crea ambientes diversos que pueden ser aprovechados. También, demuestra que a pesar de que el porcentaje entre hombre y mujeres es mayoritario con un 10\% se mantienen en una edad de 20 y 34 años (Mestanza, 2015). 
Tabla 3. Perfil sociodemográfico

\begin{tabular}{|c|c|c|c|c|}
\hline Variable & Descripción & Frecuencia & Porcentaje & $\begin{array}{l}\text { Porcentaje } \\
\text { acum. }\end{array}$ \\
\hline \multirow{2}{*}{ Sexo } & Masculino & 148 & 38,5 & 38,6 \\
\hline & Femenino & 236 & 61,2 & 100 \\
\hline \multirow{4}{*}{ Edad } & De 25 a 30 & 241 & 63,0 & 63,0 \\
\hline & De 31 a 35 & 51 & 13,2 & 76,2 \\
\hline & De 36 a 40 & 27 & 7,1 & 83,3 \\
\hline & Más de 40 & 65 & 16,7 & 100 \\
\hline \multirow{4}{*}{$\begin{array}{l}\text { Ocupación } \\
\text { actual }\end{array}$} & Servidor público & 142 & 37,0 & 37,0 \\
\hline & $\begin{array}{l}\text { Empleado pri- } \\
\text { vado }\end{array}$ & 166 & 43,1 & 80,1 \\
\hline & Jubilado & 5 & 1,3 & 81,4 \\
\hline & Empresario & 71 & 18,6 & 100 \\
\hline \multirow{4}{*}{$\begin{array}{l}\text { Gasto esti- } \\
\text { mado }\end{array}$} & $\$ 100-\$ 300$ & 246 & 64,1 & 64,3 \\
\hline & $\$ 301-\$ 600$ & 89 & 23,1 & 87,5 \\
\hline & $\$ 601-\$ 900$ & 31 & 8,0 & 95,5 \\
\hline & $\begin{array}{l}\$ 901 \text { en adelan- } \\
\text { te }\end{array}$ & 18 & 4,5 & 100 \\
\hline \multirow{5}{*}{$\begin{array}{c}\text { Con quién } \\
\text { viaja }\end{array}$} & Solo & 86 & 22,4 & 22,5 \\
\hline & Con pareia & 68 & 17,6 & 40,2 \\
\hline & & 196 & 51,0 & 91,3 \\
\hline & Familia & 34 & 8,7 & 100 \\
\hline & Amigos & & & \\
\hline
\end{tabular}

Fuente. Elaborado por los autores. 
La tabla 4 referenció al modelo de regresión múltiple para determinar su validez, mediante su análisis por tipo de red social, que se ha considerado según del Alcázar (2021) en la promoción turística. El modelo de regresión aplicado a la red social Facebook $(, 508)$, Instagram $(, 441)$ y WhatsApp $($,509) presenció un valor $r$ medianamente alto a la hora de promocionar un lugar turístico (ver tabla 4). Mientras que, el estudio denominado Redes sociales como medio de promoción turística en los países iberoamericanos, destacó que Facebook es la principal red social para obtener una promoción efectiva, dado que, cuenta con el mayor número de seguidores, publicaciones y engagement. Por otro lado, Instagram mediante sus publicaciones es considerado como promoción visual, ya que, las imágenes y videos predominan las interacciones (Gutiérrez et al., 2018).

Tabla 4. Modelo de regresión múltiple

\begin{tabular}{|lccccc|}
\hline Modelo & $\mathrm{R}$ & $\begin{array}{c}\mathrm{R} \text { cuadra- } \\
\text { do }\end{array}$ & $\begin{array}{c}\mathrm{R} \text { cuadrado } \\
\text { corregida }\end{array}$ & $\begin{array}{c}\text { Error típ. } \\
\text { de la esti- } \\
\text { mación }\end{array}$ & $\begin{array}{c}\text { Dur- } \\
\text { bin-Watson }\end{array}$ \\
\hline Facebook &, $508^{\mathrm{a}}$ &, 258 &, 225 &, 970 & 2,106 \\
\hline Instagram &, $441^{\mathrm{a}}$ &, 194 &, 159 & 1,369 & 1,673 \\
\hline WhatsApp &, $509^{\mathrm{a}}$ &, 259 &, 226 &, 779 & 1,971 \\
\hline Twitter &, $188^{\mathrm{a}}$ &, 035 &,- 007 & 1,096 & 1,862 \\
\hline Telegram &, $253^{\mathrm{a}}$ &, 064 &, 023 & 1,024 & 1,736 \\
\hline Linkedin &, $249^{\mathrm{a}}$ &, 062 &, 021 & 1,007 & 1,898 \\
\hline
\end{tabular}

Fuente. Elaborado por los autores. 
El análisis de varianza ANOVA determinó la significancia de utilización de las redes sociales y la promoción turística. Mediante el análisis del valor $p$, se logró obtener la significancia de los criterios de relación. En este punto, se pudo afirmar que: a) Facebook sí influye en la promoción de un lugar turístico, b) Instagram tiene alta significancia para promocionar un lugar turístico, y c) WhatsApp presentó relación en la promoción turística (ver tabla 5).

Tabla 5. Análisis de varianza (ANOVA)

\begin{tabular}{|lccccc|} 
& $\begin{array}{c}\text { Suma de } \\
\text { cuadrados }\end{array}$ & gl & $\begin{array}{c}\text { Media } \\
\text { cuadrática }\end{array}$ & F & Sig. \\
\hline Facebook & 97,048 & 13 & 7,465 & 7,936 &, $000^{\mathrm{b}}$ \\
\hline Instagram & 134,085 & 13 & 10,314 & 5,505 &, $000^{\mathrm{b}}$ \\
\hline WhatsApp & 62,928 & 13 & 4,841 & 7,969 &, $000^{\mathrm{b}}$ \\
\hline Twitter & 13,072 & 13 & 1,006 &, 837 &, $620^{\mathrm{b}}$ \\
\hline Telegram & 21,352 & 13 & 1,642 & 1,567 &, $094^{\mathrm{b}}$ \\
\hline Regresión & 19,856 & 13 & 1,527 & 1,506 &, $114^{\mathrm{b}}$ \\
\hline
\end{tabular}

Fuente. Elaborado por los autores.

En la figura se detallan los coeficientes de relación del modelo teórico, en el cual, se especifica su comportamiento relacional entre variables. 


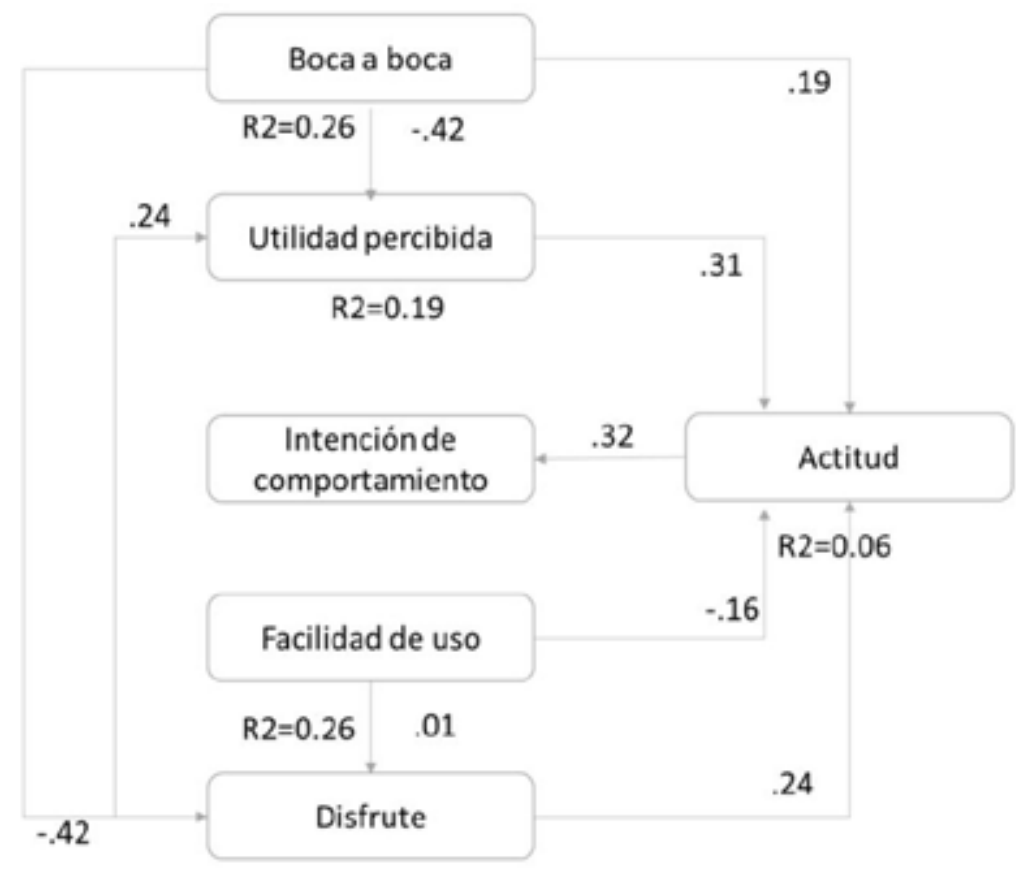

Figura 3. Modelo teórico de aceptación y tecnología.

Fuente. Elaborado por los autores.

El análisis de coeficientes beta de la tabla 6, determinó las causas de la utilidad percibida y la facilidad de uso según el modelo TAM. En este punto, se pudo identificar que Facebook $(, 012)$ mantiene una relación directa como utilidad de herramienta estratégica para promocionar un lugar turístico. Por tanto, el estudio denominado Efectividad de la publicidad en Facebook: un estudio sobre formatos y dispositivos de acceso estableció que el incremento de visitas y compras se produjo después de promocionar el producto en dicha red social, pues, subió de un $28 \%$ al $76 \%$ (Molina, 2015).

Instagram, por otro lado, mantuvieron causas de utilidad percibida en: Popular entre los consumidores para compartir experiencias personales, comentarios y opiniones (,02); las redes sociales son consideradas como una herramientas de comunicación de boca a boca $(, 01)$; Las redes sociales permiten difundir contenidos publicitarios a gran escala $(, 00)$; 
Las empresas pueden tener una mala publicidad del uso de las redes sociales $(, 04)$; Los spammers son un problema para nuevos usuarios $(, 03)$; las redes sociales pueden difundir comentarios negativos fácilmente, lo que puede dañar una empresa $(, 09)$.

Al mantener un valor $p$ cercano a 0 . El estudio Redes sociales como medio de promoción turística en los países iberoamericanos, asegura que, Instagram al considerarse una plataforma visual, mantiene una mayor interacción de los consumidores a través de imágenes, videos, comentarios y follows, por lo tanto, la dinámica puede llegar hacer beneficiosa para el sector turístico como para su entorno (Gutiérrez Montoya, Sánchez Jiménez, \& Galiano Coronil, 2018).

WhatsApp percibe una causa de utilidad en: Popular entre los consumidores para compartir experiencias personales, comentarios y opiniones (,01); Las redes sociales permiten presentar contenidos publicitarios dinámicos (,11), pues, es considerada una plataforma de comunicación y difusión. Sin embargo, el reporte Herguedas (2017) denominado Integral Media: WhatsApp Business, la manzana que todos desean morder, asevera que es una herramienta de mensajería indispensable, pues, permite automatizar, organizar y responder rápidamente a los clientes, facilitando la información de manera rápida y eficaz. 
Tabla 6. Análisis de coeficientes beta

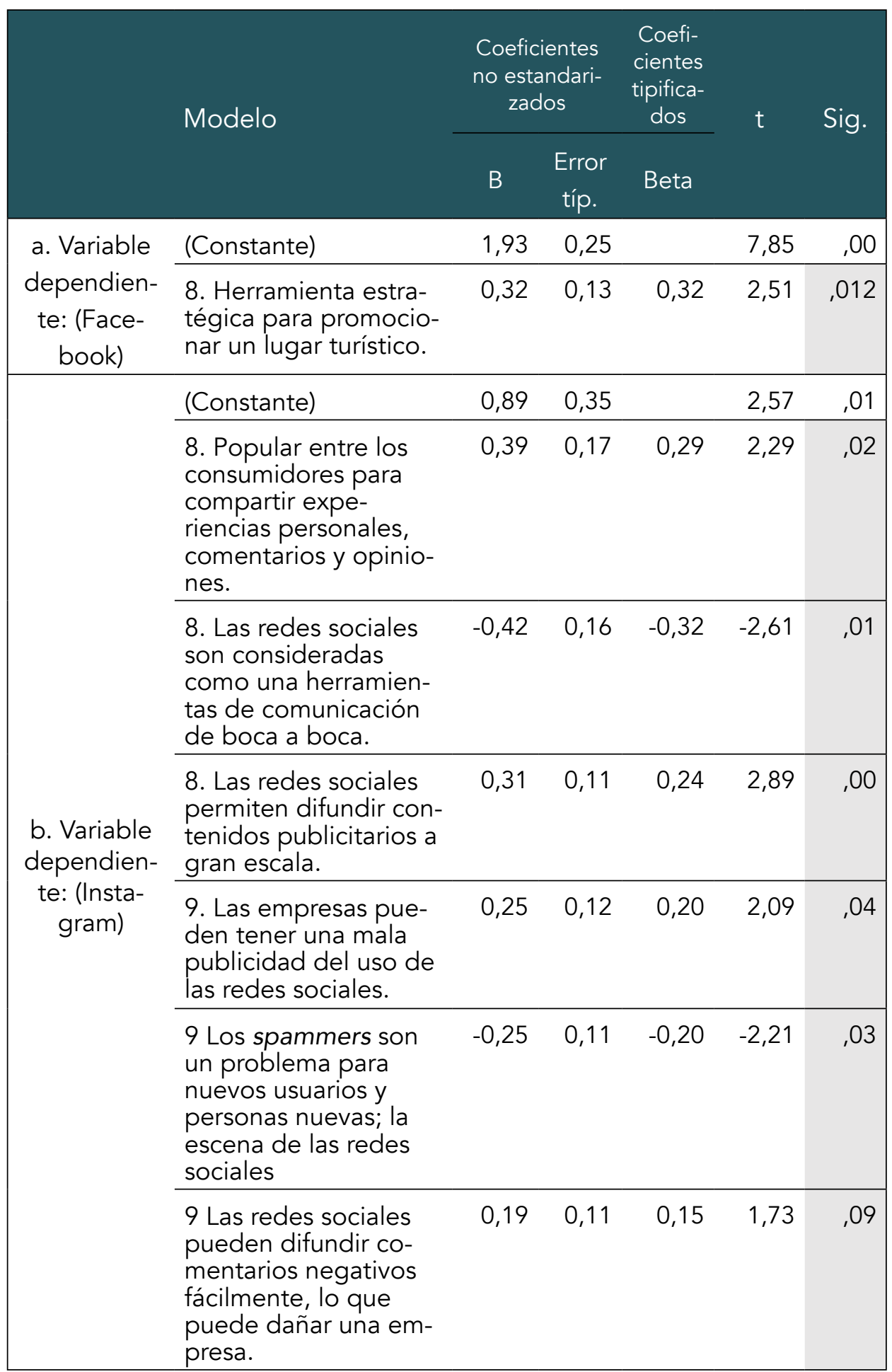




\begin{tabular}{|c|c|c|c|c|c|c|}
\hline \multirow{3}{*}{$\begin{array}{c}\text { c. Variable } \\
\text { depen } \\
\text { diente: } \\
\text { (WhatsApp) }\end{array}$} & (Constante) & 2,79 & 0,20 & & 14,10 & ,00 \\
\hline & $\begin{array}{l}\text { 8. Popular entre los } \\
\text { consumidores para } \\
\text { compartir expe- } \\
\text { riencias personales, } \\
\text { comentarios y opinio- } \\
\text { nes. }\end{array}$ & 0,24 & 0,10 & 0,30 & 2,46 & ,01 \\
\hline & $\begin{array}{l}\text { 8. Las redes sociales } \\
\text { permiten presentar } \\
\text { contenidos publicita- } \\
\text { rios dinámicos. }\end{array}$ & $-0,16$ & 0,10 & $-0,20$ & $-1,60$ &, 11 \\
\hline
\end{tabular}

Fuente. Elaborado por los autores. 


\section{Conclusiones}

a revisión literaria demostró que las redes sociales son una herramienta de comunicación masiva (Singh, 2019), puesto que, la publicación en fotos o videos de lugares que visitan se reproduce de manera viral en las plataformas de mayor uso. Por otro lado, Kovathanakul (2015) argumentó que la información que se otorga acerca de los destinos turísticos es influenciado impulsivamente en la intención de compra por el número de reproducciones o comentarios de manera positiva 0 negativa en las plataformas digitales.

Se pudo verificar, mediante los análisis de coeficientes de beta, que la utilidad percibida por el turista facilita el proceso de compra, así como la influencia de la elección del destino turístico. Es decir, que las plataformas digitales pueden llegar a tener cierto nivel de influencia directa en la precepción e imagen que se tiene de un lugar, ciudad o país, pues, su difusión permite generar una comunicación efectiva. También, se debe considerar que al compartir, informar, comentar y difundir experiencias se mantiene un vínculo con el consumidor; por tanto, se pudo afirmar las hipótesis planteadas en el estudio. 
Los resultados reflejaron que Instagram posee una mayor relación con el modelo planteado, pues, a pesar de ser la segunda plataforma más usada, su influencia en el sector del turismo tiene mayor dominio. Es por ello que, la popularidad que posee entre los consumidores como una herramienta de comunicación, puede generar contenidos publicitarios a gran escala.

Se pudo concluir también que, las redes sociales son herramientas que facilitan las estrategias comerciales, pues, buscan potenciar la distribución promocional de sus bienes o servicios. En el caso del sector turístico, dichas plataformas fomentan el turismo nacional y el crecimiento de la afluencia económica. Desde este punto, se pudo ultimar que Instagram posee mayores interacciones visuales por videos, imágenes y followers, lo que dio cabida a la alta relación que posee la plataforma con la difusión del entorno turístico. Facebook, a pesar de poseer más de 14 millones de usuarios, la relación con el modelo planeado es medianamente baja. 


\section{Referencias}

Alfonso, R., García, N., \& Rodríguez, A. (2017). Promoción Turística basada en una herramienta web para el cantón Bolívar, Ecuador. Revista ECA Sinergia. Facultad de Ciencias Administrativas y Económicas, 32(2), 117-123.

Bodle, R. (2015). Teaching Arts and Science with the New Social Media Article information: Cutting-Edge Technologies in Higher Education, (Vol. 3). Emerald Group Publishing Limited. https://doi.org/10.1108/S20449968(2011)0000003009

Castillo, M., \& Cataño, V. (2015). La promoción turística a través de técnicas tradicionales y nuevas. Redalyc, 24, 737-757.

Cortés, M., \& Alcantara, A. (2010). Predicciones Social Media 2010. Interactividad, 12(4), 1-31.

del Alcázar, P. J. (2021). Ecuador Estado Digital Enero 2021. Mentinno - Innovation \& Lifetime Value Partners.

Di Pietro, L., Di Virgilio, F., \& Pantano, E. (2012). Social network for the choice of tourist destination: Attitude and behavioural intention. Journal of Hospitality and Tourism Technology, 3(1), 60-76. https://doi. org/10.1108/17579881211206543

Félix, Á., \& García, N. (2020). Estudio de pérdidas y estrategias de reactivación para el sector turístico por crisis sanitaria COVID-19 en el destino Manta-Ecuador. Revista internacional de turismo, empresa y territorio, 1(1), 79103. https://doi.org/10.21071/riturem.v4i1.12743

García, L., \& Sánchez, R. (2014). Las redes sociales como herramienta de mejora de la experiencia turística: Una aplicación al sector hotelero. Revista Iberoamericana de Turismo, 4(41), 16-34. http://www.seer.ufal.br/index. php/ritur

Gulati, S. (2021). Social and sustainable: exploring social media use for promoting sustainable behaviour and demand amongst Indian tourists. International Hospitality Review, 10(11), 1-21. https://doi.org/10.1108/ihr-12-2020-0072

Gutauskas, A. F. (2019). Comunicación responsable de una marca turística en crisis : el caso de Villa la Angostura en la erupción del volcan Puyehue. Revista Comunicación, 12(22), 53-68.

Gutiérrez, G., Sánchez, M. Á., \& Galianol, A. (2018). Redes sociales como medio de promoción turística en los países iberoamericanos. Revista de Ciencias de la Administración y Economía, VIII(15), 135-150. 
Gutiérrez Montoya, G., Sánchez Jiménez, M. Á., \& Galiano Coronil, A. (2018). Redes sociales como medio de promoción turística en los países iberoamericanos. Revista de Ciencias de la Administración y Economía, VIII(15), 135150.

Herguedas, M. (2017). Integral Media: Whatsapp Business, la manzana que todos desean morder.

Joel, R., \& Armas, M. De. (2021). Comportamiento de la producción científica sobre el marketing digital indizada en la base de datos SCOPUS, en el período 2016-2019. Revista Científica Bibliotecas anales de investigación, 17(1), 27-39.

Khan, S., Abduljabbar, A., \& Alsamarai, S. (2019). Social media and its adverse effect on academic performance of students. Bulletin of Social Informatics Theory and Application, 3(1), 38-44.

Kovathanakul, D. (2015). Central Northeastern Thailand Tourism Branding, Supporting the ASEAN Economic Community. Procedia Economics and Finance, 23(October 2014), 291-297. https://doi.org/10.1016/s22125671(15)00469-4

Mestanza, L. M. (2015). Las Redes Sociales y el Turismo Importancia de las redes sociales sobre la estrategia empresarial del sector turístico. Trabajo de fin de grado.

Molina, A. M. (2015). Efectividad de la publicidad en Facebook : un estudio sobre formatos y dispositivos de acceso.

Nazimsha, \& Rajeswari. (2018). Comparing Digital Marketing With Traditional Marketing and Consumer Preference Over Which Medium by Taking Concept of Ads. International Journal of Sales \& Marketing Management (IJSMM), 7(1), 1-12. Recuperado de http://www.iaset.us/view_archives. php?year $=2018 \&$ jtype $=2 \&$ id $=33 \&$ details $=$ archives

Organizacion Mundial de Turismo. (2020). Covid - 19 y turismo 2020: análisis del año.

Sanchis, S. (2013). La comunicación y las redes sociales. Revista de investigación, 2(1), 4. https://doi.org/10.17993/3ctic.2013.21

Sharma, A., \& Bhatnagar, J. (2016). Enterprise social media at work: webbased solutions for employee engagement. Human Resource Management International Digest, 24(7), 16-19. https://doi.org/10.1108/HRMID-04-2016-0055

Singh, A. (2019). E-Word of Mouth : Strengthening the Strategic Tool of Digital Marketing. International Journal of Recent Technology and Engineering (IJRTE), 2(2), 921-926. https://doi.org/10.35940/ijrte.B1114.0982S1019 